\title{
Fair Value Measurement of Investment Real Estate: Deregulation or Lack of Coordination?- Research Based on China's Capital Market Data
}

\author{
Zhang Qingyu1, a \\ ${ }^{1}$ Henan University of Animal Husbandry and Economics, School of Finance and Accounting, \\ Zhengzhou, Henan, China \\ a1103498281@qq.com
}

Keywords: Investment real estate; Fair value; Valuation techniques; the asset appraisal.

\begin{abstract}
In China's capital market, the number of listed companies measuring investment real estate at fair value is gradually increasing. They have obvious industry and regional characteristics, and mainly rely on external professional appraisers to evaluate the fair value. By analyzing the financial reports of listed companies, we found that some regulation are contrary to the accounting standards for investment real estate: according to the third level parameter valuation, coexistence of bot the cost and fair value measurement modes, accounting standards are not in accordance with the guidance of investment real estate evaluation. We should improve the guidelines for the application of investment real estate accounting standards, issue specific explanations or application cases of investment real estate evaluation opinions, strengthen the publicity and popularization of accounting standards, implement joint supervision of accounting, securities and evaluation industries, improve the quality of fair value information of investment real estate, and make the reform of accounting standards better serve the development of capital market.
\end{abstract}

\section{投资性房地产公允价值计量：放松管制还是缺乏协调？ \\ --基于中国资本市场数据的研究}

\author{
张清玉 $^{1,}$ a \\ 1河南牧业经济学院金融与会计学院，郑州,河南，中国 \\ a1103498281@qq.com
}

关键词：投资性房地产；公允价值；估值技术；资产评估

中文摘要. 中国资本市场以公允价值计量投资性房地产的上市公司数量逐步增加, 行业、地 区特征明显，且主要依靠外部专业评估师对公允价值估值。通过分析上市公司财务报告，发 现存在有悖于投资性房地产会计准则的规定: 依据第三层次参数估值, 成本与公允价值两种 后续计量模式并存，会计准则与投资性房地产评估指导意见不一致。应当通过完善投资性房 地产会计准则应用指南, 发布投资性房地产评估意见具体解释或应用案例, 加强会计准则宣 传与普及，实施会计、证券、评估行业联合监管，提升投资性房地产公允价值信息质量，使 会计准则改革更好服务于资本市场发展。

\section{1. 引言}

以公允价值计量投资性房地产，可以全面及时反映投资性房地产的现行价值及市场对未 来经济环境的预期，增强会计信息的决策相关性。通过查阅资本市场上A股公司年度财务报 
告, 以公允价值对投资性房地产进行后续计量的公司, 已由 2007 年的 20 家增加到2017年底的 96家，而占A股拥有投资性房地产公司的比例不到 $6 \%$ 。这与我国会计准则体系谨慎使用公允 价值，尤其是对非金融资产使用公允价值的严格限制条件密切相关，也反映我国现行投资性 房地产市场的整体状况，符合我国现阶段市场经济发展的实际。

作为非金融资产应用公允价值计量的先行，投资性房地产公允价值计量的研究成果丰硕， 主要集中于选择动因、财务后果、价值相关性等方面。在投资性房地产公允价值计量选择动 因上：公允价值计量可以降低信息不对称（Muller et.al., 2008; Quagli et.al., 2010; 陈鹰, 2010），降低企业债务违约风险（Cotter and Zimmer，1995; Christensen and Nikolesv，2013; 王福胜，程富，2014；周玮、徐玉德，2014），也可以提高财务信息透明度（Karl A. Muller, III et.al., 2008）。同时, 我国房地产上市公司在选择公允价值计量时并不是完全理性的,存在 明显的趋同效应（陈鹰, 2010; 刘斌和熊运莲, 2010)。在投资性房地产公允价值计量的财 务后果上: 与历史成本计量模式相比，投资性房地产采用公允价值计量将大幅提高其账面价 值, 同时也会增加净利润的波动（张奇峰、张鸣等, 2011）。选择公允价值计量投资性房地 产很可能会成为上市公司操纵盈余的一个工具（陈晨，2012），这与邹燕等（2013）案例研 究得到的结论相一致。而与之相反, 陈鹰 (2010) 研究发现, 公允价值计量模式的选择与企 业期望的收益平滑活动负相关。在投资性房地产公允价值计量的价值相关性上：2007年执行 新会计准则后, 我国上市公司对投资性房地产运用用公允价值与股票价值具有价值相关性，会 计信息的决策有用性有所提高（刘运国、易明霞，2010）；季晓婷、邵小航（2014）以拥有 投资性房地产的 $\mathrm{A} 、 \mathrm{H}$ 股上市公司为样本，发现公允价值模式计量的投资性房地产信息比成本 模式计量的价值相关性更强。

当前投资性房地产公允价值计量研究，主要采用投资性房地产公允价值数据直接进行实 证检验，前提是假定投资性房地产公允价值信息真实可靠。而尚没有研究探讨投资性房地产 公允价值计量本身存在的现实问题。本研究通过分析上市公司财务报告, 发现投资性房地产 公允价值计量存在输入参数与会计准则要求不一致、成本与公允价值计量模式并存以及会计 准则与投资性房地产评估意见不一致等问题。应采取完善投资性房地产会计准则的操作指南, 发布投资性房地产评估具体解释或应用案例, 加强投资性房地产、公允价值计量等会计准则 的宣传与普及，并建议会计准则制订与监管机构、评估监管机构联合执法，强化投资性房地 产公允价值评估监管，以提升投资性房地产公允价值信息质量，更好服务于信息使用人决策 需求。

\section{2. 中国资本市场投资性房地产公允价值计量概况}

\section{1 上市公司以公允价值计量投资性房地产的整体情况}

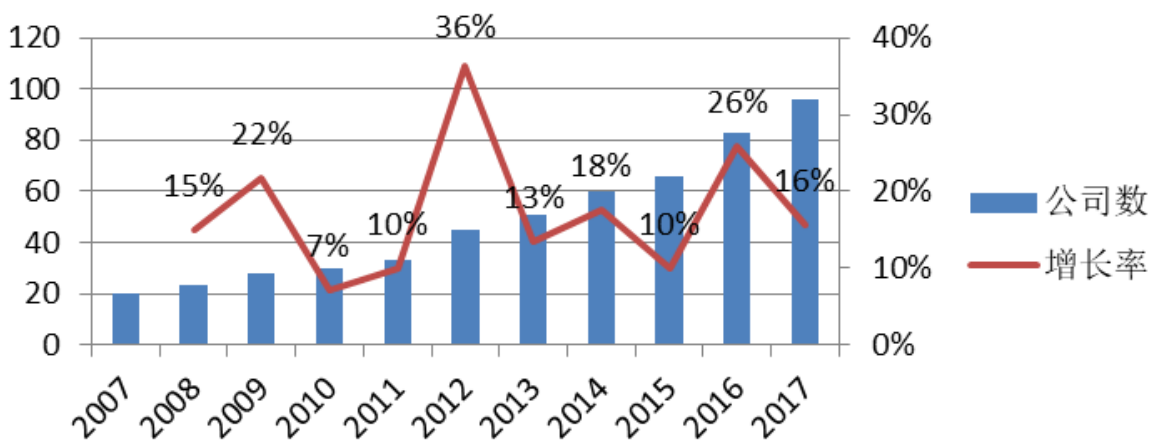

图 1 20007-2017 年以公允价值对投资性房地产后续计量的 A 股上市公司

整体来看，作为2007年会计准则新增加项目，拥有投资性房地产的A股上市公司比例在 各年度均超过半数, 投资性房地产以公允价值后续计量的上市公司也呈现缓慢上升趋势, 在 
2017年底已有96家上市公司采用公允价值计量投资性房地产，而占全部上市公司的相对比例 仍然较低，基本保持在3\%以下。说明我国上市公司更偏好于成本模式而非公允价值模式对投 资性房地产进行后续计量（谢获宝等，2011；王小力，2012）。

\section{2 以公允价值计量投资性房地产上市公司的行业与地区分布}

表 1 运用公允价值计量投资性房地产的上市公司行业统计

\begin{tabular}{|c|c|c|}
\hline 所属行业 & 公司数量 & 占比 $(\%)$ \\
\hline 制造业 & 31 & 32.63 \\
\hline 房地产业 & 26 & 27.37 \\
\hline 金融业 & 9 & 9.47 \\
\hline 批发和零售业 & 8 & 8.42 \\
\hline 租赁和商务服务业 & 6 & 6.32 \\
\hline 其他行业 & 16 & 15.79 \\
\hline 合计 & 96 & 100 \\
\hline
\end{tabular}

据表1统计分析，制造业、房地产业和金融业类公司对投资性房地产采用公允价值后续计 量最多, 分别为 31 家和 26 家，两类公司合计占全部运用公允价值计量投资性房地产公司的比 例达到60\%，行业分布特征明显。制造业类上市公司对投资性房地产采用公允价值计量的最 多, 主要原因在于制造类公司数量最多, 在所有行业中占比最大; 另外, 随着房地产市场持 续升温，制造业是否存在脱离主业而通过投资性房地产公允价值的计量而进行盈余管理，“脱 实向虚”的倾向值得关注。房地产业是投资性房地产的主要分布行业, 以公允价值反映所持有 的投资性房地产更能体现资产的现行价值, 更能满足信息使用人决策需求; 同时, 公司由经 营住宅房地产转变为经营商业地产的经营战略转变, 也是房地产企业选择公允价值计量的主 要动因（戴佳君、季晓婷等, 2010）。

从地区分布看，以上市公司注册地或主要经营所在地为统计标准，有65家上市公司注册 地均位于东部地区, 17家上市公司位于西部地区, 10 家上市公司位于中部地区, 注册地位于 东北地区仅有2家上市公司。进一步统计注册地的具体分布，发现近95\%的上市公司注册地均 位于市区，位于县城的有3家上市公司（金正大、羚锐制药、舍得酒业），另外还有金龙股份 公司的注册地在乡镇。可以看出, 活跃市场是公允价值计量的必要条件。我国市场化程度呈 现明显的区域差异, 我国东部地区上市公司所在地市场化程度越高, 相关资产或负债的交易 市场活跃度高, 公允价值比较客观合理, 获取成本也较低, 上市公司更可能选择公允价值计 量（颜敏等，2011; 张黎，2013）。

\section{3 投资性房地产公允价值确定方法与输入值层次}

表 22017 投资性房地产公允价值输入值层次与公允价值确定方法

\begin{tabular}{|c|c|c|c|}
\hline 输入值层次 & 公司数量 & 确定方法 & 公司数量 \\
\hline 第一层次 & 8 & 专业资产评估机构评估 & 67 \\
\hline 第二层次 & 48 & 活跃市场上同类或类似房地产现行价格 & 22 \\
\hline 第三层次 & 32 & 独立专业评估师评估或潜在第三方购买报价 & 2 \\
\hline 第二和第三层次 & 1 & 未具体披露确定方法 & 5 \\
\hline 未具体披露输入值层次 & 7 & 合计 & 96 \\
\hline 合计 & 96 & & \\
\hline
\end{tabular}

以2017年投资性房地产公允价值计量为例，统计发现，有67家上市公司选择聘请具备专 业评估资质的评估机构计量投资性房地产的公允价值，占比达到 $69.79 \%$ ，参考活跃市场上同 类或类似房地产现行价格的有 22 家，占比 $22.92 \% ， 2$ 家公司采用独立专业评估师评估或潜在第 三方购买报价，有5家公司未具体披露投资性房地产公允价值的确定方法，上市公司主要依靠 
专业评估机构来评估公允价值, 专业评估机构对公允价值评估质量的好坏直接影响我国资本 市场投资性房地产公允价值信息质量的高低。

由上市公司披露的投资性房地产公允价值输入值（参数）的计量层次可以看出，采用第 二、三层次输入值来计量公允价值的上市公司有 81 家，占比达 $84.38 \%$ ，仅以第一层次输入值

(即计量日能取得相同资产或负债活跃市场未经调整报价) 来计量公允价值的只有 8 家，占比 $8.33 \%$, 还有 7 家上市公司未披露公允价值的计量所依据的输入值层次。第二层次输入值主要 是类似资产活跃市场报价，或非活跃市场中相同或类似资产报价，第三层次输入值是不可观 察的输入值, 主要是依靠评估人员的所掌握的私有信息而非市场公开信息来进行公允价值估 值。就投资性房地产的输入值来看, 很少存在相同投资性房地产的活跃市场报价, 主要依靠 类似资产市场报价或未来现金流量折现，而这都会涉及重大主观估计和职业判断，与我国投 资性房地产市场发展的实际情况相吻合。

\section{3. 投资性房地产公允价值计量的现实困惑与原因分析}

理论而言，作为非金融资产，以公允价值对投资性房地产进行后续计量，可以提供投资 性房地产的现行价值, 反映投资性房地产市场环境的未来不确定性。作为稀缺资源, 房地产 市场价格飞速鄃风升，若作为固定资产或无形资产，采用单一历史成本计量属性，必然出现房 地产账面价值与其市场价值的严重偏离，历史成本不能反映资产真实价值的弊端暴露出来。 而投资性房地产的公允价值更能反映资产的现实情况, 准确地向投资人报告资产的及时价格 信息，有利于投资人进行决策。

就现实选择看，在西方市场经济发达国家，相对于其他非金融资产，投资性房地产具有 流动市场, 取得公允价值成本较低, 投资性房地产主要运用公允价值进行计量。究竟是选择 更能反映市场价值的公允价值, 还是沿袭传统选择对利润波动影响较少的历史成本, 中国更 多上市公司做出了保守的选择。

现行采用公允价值对投资性房地产后续计量的上市公司尽管数量少，而示范效应明显， 尤其是随着我国房地产市场逐步成熟，投资者对信息相关性的追求，投资性房地产公允价值 运用是大势所趋。而如果不从根源上解决投资性房地产公允价值计量的现实难题，对于进一 步理论研究以及实务决策都造成困难。通过查阅上市公司财务报告, 发现投资性房地产应用 公允价值后续计量存在如下问题。

\section{1 投资性房地产公允价值计量的输入值与会计准则要求不一致}

《企业会计准则第3号--投资性房地产》第十条规定，有确丵证据表明投资性房地产的公 允价值能够持续可靠取得的, 可以对投资性房地产采用公允价值模式进行后续计量。采用公 允价值模式计量应同时满足下列条件：投资性房地产所在地有活跃的房地产交易市场；企业 能够从房地产交易市场上取得同类或类似房地产的市场价格及其他相关信息，从而对投资性 房地产的公允价值作出合理的估计。房地产准则应用指南又进一步对房地产“所在地”、“同类 或类似”房地产进行了具体说明。

也就是说，投资性房地产后续计量采用公允价值必须有活跃市场作为支撑，对公允价值 计量整体重要的输入值必须是从活跃市场上取得的可观察输入值, 主要是“同类或类似房地产 的市场价格及其他相关信息”，这些输入值的基本特征是“可观察”，即可以在市场上直接或间 接取得，或者可以被市场所验证。按照《企业会计准则第39号--公允价值计量》，这些输入 值应当归属于第一或第二层次，而绝不可能是第三层次输入值，因第三层次输入值是“不可观 察输入值”, 是需要公允价值评估人员主要利用主观估计和判断, 利用内部数据进行的公允价 值估值。

经统计, 2017年报中将投资性房地产公允价值计量输入值层次划分为第三层次的有32家， 即有三分之一的上市公司计量投资性房地产所采用的重要输入值是不可观察输入值, 明显违 
背投资性房地产会计准则的要求。进一步, 划分为第三层次输入值的32家公司中, 公允价值 的具体确定方法有 8 家采用的是“活跃市场上同类或类似房地产的现行价格”，应当属于第二层 次输入值来进行披露, 显然是错误理解了公允价值计量准则中公允价值层次的概念。

\section{2 存在历史成本与公允价值两种后续计量模式并用情况}

投资性房地产准则应用指南提出，企业通常应当采用成本模式对投资性房地产进行后续 计量, 也可采用公允价值模式对投资性房地产进行后续计量。但同一企业只能采用一种模式 对所有投资性房地产进行后续计量, 不得同时采用两种计量模式。之所以这样规定, 是会计 准则出于 “谨慎”运用公允价值的背景下，防止上市公司利用投资性房地产公允价值计量来调 节利润所致（马永义，2015），是会计准则“在一定程度上抑制公司利润操纵行为”的功能定 位的体现（沈烈, 2013）。

方大集团（000055）披露年报显示，同时存在以成本和公允价值两种模式后续计量的投 资性房地产。审计师在致监管部门问询函的回复中指出, 由于存在对外出租的空置厂房所在 地不存在活跃交易市场，无法取得同类或类似房地产市场价格及其他相关信息，只能作为特 殊情形对其采用成本模式进行后续计量。因此，区分不同性质不同交易活跃程度的投资性房 地产分别采用不同的后续计量模式。

诚然，同一集团分布在不同城市的子公司可以考虑根据市场活跃程度采用不同的计量模 式（刘永泽，2010），这要比“严格”采用一种计量模式能更好反映投资性房地产的现实情况， 提供更相关的高质量会计信息。而上市公司必须予以充分披露，注册会计师要严格核查，监 管部门要强化监管。为了保证会计信息可比, 成本与公允价值模式同时采用的现象只能是“特 殊情况”, 绝不能由此产生“示范效应”而成为常态, 因这不仅与当前市场条件下谨慎使用公允 价值的要求相悖, 还可能成为上市公司操纵利润的一种工具。

\section{3 会计准则与投资性房地产评估指导意见在公允价值评估实践中缺乏协调}

2017年9月由中国资产评估协会正式发布的《投资性房地产评估指导意见》明确指出，本 指导意见所称投资性房地产是指《企业会计准则第3号一投资性房地产》及其应用指南所称的 投资性房地产; 执行投资性房地产评估业务，应当充分理解相关会计准则的要求、评估对象 在企业财务报告中的核算和披露要求。指导意见进一步提出, 评估投资性房地产公允价值主 要采用市场法和收益法。

市场法采用的主要是同类或类似房地产的市场交易信息; 而收益法评估既可能采用公开 可观察的市场信息，也可能采用基于资产评估师或管理层自身的假设、判断得到的不可观察 信息，如果采用后者，说明投资性房地产不存在可以持续取得公允价值的活跃市场，不再符 合会计准则中以公允价值对资性房地产后续计量的两个必备条件, 不能采用公允价值模式来 计量。而《投资性房地产评估指导意见》对采用收益法来评估投资性房地产的公允价值并未 明确可以采用的输入值的类型，很容易导致评估师的误用。

由表2知，2017年对投资性房地产采用公允价值后续计量的96家上市公司中，通过专业资 产评估机构评估来确定公允价值的有 67 家, 占比 $69.79 \%$ 。进一步查阅, 发现这些上市公司中 又有 24 家 $(36 \%)$ 将投资性房地产公允价值估值所采用的是第三层次不可观察输入值, 明显 与会计准则规范不一致。

投资性房地产公允价值计量实务存在与会计准则不一致、与投资性房地产评估意见不协 调之处，是放松了对公允价值应用的管制，准则实施以来“谨慎”应用公允价值的态度有所放 松? 还是投资性房地产会计准则、公允价值计量准则与投资性房地产评估指导意见之间缺乏 有效的协调一致?

由公开发布的证券交易所管理部对涉及投资性房地产公允价值计量对上市公司的问询 函, 以及近年来监管部门发布的上市公司运用会计准则监管报告中对公允价值的关注看, 证 券监管部门并未放松管制, 公允价值计量尤其是缺乏活跃市场时公允价值计量仍然是监管的 
重点。主要原因还在于会计准则及其指南存在需要进一步完善之处, 如投资性房地产公允价 值模式在哪些情况下可以与历史成本模式并存? 聘请专业评估机构时, 评估师执业中如何保 持与会计准则的一致性？如何保证投资性房地产公允价值信息的质量而与会计准则“谨慎”运 用公允价值的基调相一致？如何披露公允价值的确定依据（同类或类似房地产的市场价格及 其他相关信息）？投资性房地产公允价值计量出现的现实困惑，对公允价值计量等会计准则 理解不深入，会计准则缺乏与资产评估意见的协调一致是主要原因。

\section{4. 改善投资性房地产公允价值计量的措施}

\section{1 完善投资性房地产会计准则的操作指南}

投资性房地产会计准则于2006年发布，准则提出了公允价值后续计量模式的选择，而由 于受到对公允价值本质认识所限，在公允价值界定、活跃市场的判断、公允价值层次、计量 参数选择以及如何判断房地产的最佳用途等方面没有规范。2014年初公允价值计量准则发布, 统一了公允价值的脱手价格定位, 界定了公允价值的输入值层次, 明确了公允价值的估值技 术, 尤其是专门列章节对非金融资产公允价值计量进行明确, 因此, 需要修订投资性房地产 准则或者应用操作指南, 明确解释公允价值计量可能存在的与历史成本模式并存问题, 保持 与公允价值计量准则保持公允价值计量的一致性, 明确投资性房地产公允价值计量的输入值 层次选择、不同估值技术的采用、有序交易市场的判断、规范信息披露。

\section{2 发布投资性房地产评估具体解释或应用案例}

不同于存在活跃市场的多数金融资产，投资性房地产活跃市场相对较少，依靠活跃市场 报价来直接获取投资性房地产的公允价值难度较大。鉴于投资性房地产公允价值计量的难度， 多数以公允价值计量投资性房地产的上市公司（近70\%）都选择了以专业资产评估机构评估 来确定公允价值。为提升投资性房地产公允价值评估质量, 在财政部指导下, 中国资产评估 协会于2017年9月8日专门修订发布了《投资性房地产评估指导意见》，意见第二条明确“本指 导意见所称投资性房地产，是指《企业会计准则第3号--投资性房地产》及其应用指南所称的 投资性房地产”，可以说是中评协发布该指导意见就是为第3号会计准则的实施，而在财政部 统一部署下的“有意而为之”，是根据投资性房地产评估市场的现状，解决上市公司在投资性 房地产评估上的难题，旨在提升投资性房地产公允价值的信息质量。该指导意见明确了投资 性房地产公允价值评估的市场法与收益法, 尤其对采用收益法所依据的参数进行了规范, 如 租金收益、相应费用、净收益、收益期限、折现率等。而依据公允价值计量准则（CAS39）, 评估师在采用这些参数进行公允价值估值时, 这些参数应当是活跃市场上取得的可观察输入 值，才符合投资性房地产会计准则中采用公允价值后续计量的条件，否则就不能采用公允价 值计量, 更谈不上要进行公允价值评估了。因此, 针对多数上市公司投资性房地产公允价值 都依靠外部评估机构的实际情况, 应发布投资性房地产评估具体解释或应用案例, 进一步规 范评估指导意见的使用，提高与投资性房地产、公允价值计量等会计准则所要提供信息的一 致性。

\section{3 加强投资性房地产、公允价值计量等会计准则的宣传}

上市公司投资性房地产公允价值计量存在与成本模式并存、与公允价值计量准则要求不 一致问题，说明上市公司以及专业资产评估人员对投资性房地产准则对于公允价值后续计量 的规定、公允价值基本概念理解不到位，市场参与者、估值技术、输入值等不能准确应用。 另外, 上市公司年报经注册会计师审计后才对外发布, 存在这些问题说明注册会计师行业中 也存在对投资性房地产公允价值计量相关理念认知不足。因此, 会计准则制订机构要加强公 允价值计量准则的宣传教育与普及，提升会计人员、注册会计师及专业资产评估人员对公允 价值基本理念的认知水平，提升上市公司披露的公允价值信息质量。另一方面，扩大会计准 
则宣传教育与普及教育, 增强投资者信息解读能力对于我国现行资本市场发展具有现实意义。 目前我国资本市场上整体仍是以中小投资者为主的情况下，个人投资者能否正确解读公允价 值信息，直接影响会计准则改革服务资本市场的效果。

\section{4 会计准则制订与监管机构、评估监管机构联合执法, 强化投资性房地产公允价值评估监 管}

投资性房地产会计准则中明确，只有“存在活跃市场”且“能从市场上持续取得市场价格及 其他信息”才能进行公允价值计量，这种谨慎运用公允价值的规定尽管是2006年的规定，而与 我国房地产市场的现行实际情况仍然适应, 因此应严格实施。而由于职能存在分工, 就需要 由财政部、证监会牵头，协调中国注册会计师协会、中国资产评估协会以及相关职能监管部 门, 共同对投资性房地产公允价值计量进行联合监管, 协调相关准则、评估意见，共同治理 公允价值评估中的不一致问题，提高公允价值信息质量，更好服务于资本市场投资者对会计 信息决策相关性的需求。

\section{致谢}

本文为河南省软科学研究计划项目《公允价值信息披露与审计师关注-基于资本市场数据 的实证研究》 (192400410343)、河南牧业经济学院科研创新团队建设计划项目 (2018KYTD03) 的阶段性成果之一。

\section{References}

[1] Karl A. Muller, III, Edward J. Riedl, Thorsten Sellhorn, Consequences of Voluntary and Mandatory Fair Value Accounting: Evidence Surrounding IFRS Adoption in the EU Real Estate Industry. Working Paper, August 2008.

[2] Hans B. Christensen. Valeri V. Nikolaev, Does fair value accounting for non-financial assets pass the market test? Rev Account Stud, Vol.18, pp.734-775,2013.

[3] Vera Palea, Fair value accounting and its usefulness to financial statement users[J], Journal of Financial Reporting and Accounting, Vol.12, pp.102-116,2014.

[4] Ramanna, K., \& Watts, R. L. Evidence on the use of unverifiable estimates in required goodwill impairment. Review of Accounting Studies, vol. 17, pp.749-780,2012.

[5] Chen ying, Selection of fair value measurement model for investment real estate, Research on Financial and Economic, pp.68-72,2010.

[6] Liu yongze, Ma yan, Application dilemma and countermeasures of fair value measurement model of investment real estate, Contemporary Finance and Economics, pp.102-109,2011.

[7] Hou xiaohong, Li gang, Guo ya, Marketization degree, loan contract and fair value measurement selection -- an empirical study based on the application of fair value measurement in investment real estate, Contemporary Accounting Review, vol. 5, pp.78-88.

[8] Zhang qifeng, Zhang Ming, Dai jiajun, Financial impact and determinants of fair value measurement of investment real estate: a case study of beichen industrial, Accounting Research, pp.22-29,2011. 